\title{
DI GIOVANNI, Julia Ruiz. Cadernos de outro mundo: o Fórum Social Mundial em Porto Alegre. São Paulo: Humanitas; Fapesp, 2015, 236p.
}

\author{
L Lorena Avellar de Muniagurria \\ Universidade de São Paulo, São Paulo, São Paulo, Brasil
}

DOI 10.11606/issn.2316-9133.v25i25p449-454

Em Cadernos de outro mundo, Julia Di Giovanni oferece uma entrada diferenciada para pensar um objeto sobre o qual muito já se escreveu: o famoso Fórum Social Mundial. Reservando atenção especial às formas organizacionais - que, conforme discute, longe de serem ferramentas técnicas neutras são modos particulares e engajados de se fazer política - ela consegue tratar de relações afetivas diversas, de sensibilidades políticas e de produção de memórias. Assim, ela opera a análise sobre aspectos formais e metodológicos de maneira inovadora, lançando luz sobre elementos que permaneciam inexplorados. A chave do tempo e da memória, central no livro, surge desde a introdução, inicialmente como recurso para equacionar a dupla relação que a autora estabelece com o tema pesquisado: a de uma militante-pesquisadora. Di Giovanni participara das edições do Fórum realizadas em Porto Alegre; anos depois, no âmbito do desenvolvimento de uma tese de doutorado, ela retorna às experiências vividas, produzindo uma análise que busca pensar o Fórum nos seus próprios termos e, ao mesmo tempo, explorá-lo com um olhar renovado e problematizador. A discussão sobre as metodologias e arquiteturas do evento é construída, assim, conjuntamente à da análise das formas de produção do Fórum (especialmente a partir de uma série de práticas de escrita) e à das formas de memória que ele toma e gera.

No Capítulo 1, "Escrever o Fórum: a noção de estratégia", Di Giovanni considera a centralidade da palavra escrita para a construção do Fórum como lugar político. A Carta de Princípios, as diversas análises e balanços sobre as edições do FSM e uma série de outros documentos constituem tanto as práticas como as materialidades que são o corpo mais visível do Fórum. A autora parte de uma apresentação inicial dos principais materiais textuais que trata ao longo do livro para concluir que escritos tão variados em formatos, temas e estilos são também excessivos e repetitivos, convergindo para um mesmo efeito: eles transformam a série de eventos pontuais em uma totalidade - totalidade esta pensada pelos 
proponentes e organizadores do FSM nos termos de um "processo permanente". A autora decide, então, descrever e problematizar algumas das fórmulas mais recorrentes, tomando-as não apenas como maneiras de dizer, mas também, e especialmente, como modos de fazer: "Escrever para o Fórum e escrever o Fórum são movimentos quase indistintos” (2015, p. 48). Dessa maneira, Di Giovanni interpela o FSM desde o ponto de vista das práticas que o constituem, "a começar pelas práticas discursivas: as formas contidas nos textos escritos sobre o Fórum fazem parte do que ele é, assim como o olhar de um colecionador faz parte das peças que compõem a sua coleção” (2015, p. 49).

A principal noção explorada no primeiro capítulo é a de "estratégia". Trata-se de uma categoria que permaneceu pouco problematizada por organizadores e analistas. De maneira significativa, ela é pouco referida nos documentos, apesar de ser central na construção do Fórum. Isso aponta para uma importante ambiguidade e tensão. Se, por um lado, era necessário ao menos um "sentido estratégico" para produzir os efeitos de totalização do FSM, fazendo convergir e unificar a diversidade de atores, perspectivas e discussões que tinham lugar nas suas várias edições; por outro, a preocupação em evitar uma perspectiva única tornava problemática a adoção enfática ou explícita de uma estratégia unificada. A rejeição do pensamento único devia-se ao desejo de que o Fórum não se convertesse em instância de poder a ser disputada pelos participantes dos encontros. A solução para o dilema foi adotar uma estratégia de proliferação da (e pela) diferença, proposta essa que ganhou forma na construção de um "espaço aberto", o que procurou ser garantido por meio de uma série de mecanismos organizacionais que visavam manter o lugar de poder esvaziado.

Segundo a autora, essa maneira de operar terminou por ser a própria marca do Fórum: a produção de um espaço "aberto" e "horizontal", porém regulado, fundamentado na autonomia dos membros e na neutralidade do espaço comum, de modo a que "todos" pudessem ali falar. Como consequência da adoção da diversidade como princípio, foi estipulado o veto à definição de objetivos, às tomadas de decisão e, consequentemente, à produção de declarações em nome do Fórum. Assim, estabelecendo a unidade na forma para garantir a diversidade nos conteúdos, a estratégia da proliferação da (e pela) diversidade se transforma em metodologia. Contudo, sendo "ostensivamente aberto em termos de seus princípios, o Fórum é fechado no que tange os processos decisórios mais corriqueiros” (2015, p. 77). Di Giovanni aponta que existiu, sim, hierarquização de temas e participantes, mas que isso se fez evidente nas instâncias de decisão menos visíveis: nas comissões e comitês que decidiam sobre procedimentos operacionais mais básicos, tais como que tipo de financiamentos seria aceito, onde o Fórum seria realizado, como organizar a distribuição dos grupos no espaço, que tipo de entidades poderia participar, como seriam feitas as inscrições para participação etc. 
No Capítulo 2, "Metodologia e arquitetura do espaço Fórum”, Di Giovanni aprofunda a análise que mostra como o Fórum é produzido enquanto totalidade principalmente sob o signo do "método" e como, na medida em que se diversificavam as condições políticas, sociais e culturais de sua realização (dada a itinerância de suas edições pelo mundo), seus organizadores se preocuparam com a conservação do método. Nos materiais analisados, a "metodologia" é entendida como conjunto de regras e padrões de procedimento, sendo associada ora aos "critérios para a programação" dos eventos particulares, ora à "arquitetura" do Fórum. A arquitetura era o desenho estrutural que seria responsável por estabelecer o vínculo entre a forma ocasional dos eventos pontuais e a permanência do FSM enquanto processo de reflexão coletiva. Ao analisar modalidades de inscrição, procedimentos adotados para a definição dos temas, construção de programações, definição de atividades e as mudanças de todos esses aspectos ao longo das edições do evento, a autora mostra o aparecimento de contradições internas e o esforço da organização para incorporar as críticas e aprofundar o movimento de autorreflexão. Destarte, ela termina por evidenciar que a metodologia era, na verdade, objeto de disputas: criticava-se o caráter "elitista" do uso do Centro de Convenções da PUC-RS, ou a "opacidade" da estrutura organizacional; disputavam-se recursos, projeção e público, definidos em grande medida pelo formato da programação; entidades participantes pressionavam pela inclusão de suas formas específicas de temas de trabalho como eixos "oficiais" do Fórum etc.

A metodologia surge então como ferramenta para garantir a manutenção de diferenças, responsável por produzir um "espaço aberto". O curioso - aponta a autora - é que, enquanto na pena de alguns dos principais analistas do Fórum, o método surge como aspecto fundamental da "nova forma de fazer política" à qual se almejava, nos textos das comissões e comitês de organização ele era tratado na chave de decisões ditas operacionais - e, portanto, num limite, não políticas. Mas, como bem discute Di Giovanni, a metodologia do Fórum, como qualquer outra ferramenta, não é neutra: ela constitui um modo de ação específico e deve ser pensada como operador de uma gramática política particular, que define certos modos de visibilidade, de espacialidade e de temporalidade. Isso porque ferramentas são sempre produtos de relações particulares, que se inscrevem em sua criação e em seu uso, produzindo relações também específicas.

Assim, a autora mostra como, apesar do Fórum ser proposto como uma "nova forma de fazer política", marcado pelas críticas às formas organizacionais ditas hierárquicas e institucionais, e pela busca de estruturas que se pretendem horizontais e descentralizadas, sua "arquitetura" surge, na verdade, da combinação de formas não tão novas, que combinam práticas organizativas do "universo institucional" de relações entre organizações sociais e Estado à "linguagem da auto-organização, da radicalização democrática e da reflexividade", que fora fortalecida durante o ciclo de protestos do final dos anos 1990 (2015, p. 34). Da 
mesma maneira, apesar de visar um espaço "aberto" e "horizontal", a metodologia "horizontalista" do FSM foi produzida de maneira centralizada e nunca esteve livre de "verticalismos", não tendo se oposto, tampouco, à acumulação estratégica do poder. "Muito pelo contrário", nos diz Di Giovanni: "é a defesa de procedimentos de 'não totalização' que define uma totalidade e garante, ao longo do tempo, o acúmulo de poder daqueles que dominam a linguagem do método, manipulando as categorias que ele estabelece” (2015, p. 137). Percebe-se então a necessidade de reconhecer o caráter político da metodologia do Fórum, posto que ela funciona como tecnologia de gestão de disputas por espaço e visibilidade, e também como uma base para estratégias de apropriações.

Finalmente, no Capítulo 3, "As formas da memória no Fórum Social Mundial”, Di Giovanni toma a memória como terceiro tema condutor da problematização dos sentidos do Fórum Social Mundial. Ao analisar as relações entre a experiência política e o regime temporal do qual tal experiência é produto e produtora, ela mostra que é também através de seus diferentes modos de guardar e perder, de lembrar e esquecer, que organizadores e participantes produzem o FSM como experiência política singular. E declara: "A memória, assim como a estratégia e a metodologia, não é um dado, mas uma noção composta por e sujeita a diferente usos" (2015, p. 141). Não por acaso, a memória foi também objeto de atenção por parte do Conselho Internacional, e teve lugar de destaque entre as "tarefas" responsáveis por promover a "continuidade" do Fórum. Em especial, no momento em que as edições passam a itinerar pelo mundo, a "sistematização da memória” passa a ser necessária para garantir a integridade do espírito do FSM.

As iniciativas definidas como "de memória" do Fórum foram variadas: algumas mais formalizadas do que outras; umas promovidas por comissões ou comitês da organização; outras, por iniciativa de participantes. Houve mapas, memórias da territorialização; uma série de figuras bidimensionais, como mosaico, mural, ou rede, que expressam a coesão política do Fórum; houve também o acúmulo de documentos de análise e de registros, que falam mais diretamente da concepção do Fórum como método. Todas elas, contudo, falam sobre como participantes e organizadores esperam que suas experiências sejam lembradas quer dizer, “o que é o Fórum, quando já é passado?” (2015, p. 141). Di Giovanni identifica nessas formas variadas a preponderância da operação de justaposição horizontal, e relaciona esse aspecto à horizontalidade pretendida através do método Fórum e à necessidade de produção de símbolos da convergência entre os diversos. Além disso, a memória passível de sistematização - e, portanto, reconhecida como parte do processo - é referente a coletivos, movimentos, redes e organizações inscritos nos eventos. Quer dizer: a memória do Fórum não se desvencilha de seus princípios e de sua arquitetura conceitual.

Essa série de procedimentos de produção de memória, concebida como acúmulo, parece assim destinar-se a dar permanência e visibilidade à grande multi- 
plicidade de atores, atividades e mensagens que constituem o Fórum, mas que, no entanto, jamais chegam a se confundir com ele. Da mesma maneira como, no segundo capítulo, a autora mostrou haver mais densidade e complexidade de relações políticas do que a "horizontalidade" pretendida pela metodologia, agora ela aponta que esses procedimentos e operações deixam de fora outras formas de memória do Fórum. Elas não dão conta de "restos que se dispersam, que não se encaixam em murais ou mosaicos; [de] perambulações resistentes a mapeamentos; [de] relações e espaços afetivos profundos, que não se esgotam na metáfora da 'rede'". Segundo ela, esses

vestígios do FSM não se fixam a nenhuma superfície legível, mas permanecem impregnados em corpos e gestos, inseparáveis da própria vida. Estranhos a qualquer regime de memória concebido como acumulação, preservam em sua natureza sutil e dispersiva outros, inexplorados, sentidos políticos daquelas experiências (2015, p. 142).

A consideração dessas outras formas de memória - memórias "habitadas", como sugere a certa altura a autora, posto que são relativas a "experiências concretas" (2015, p. 166) - tem como objetivo tentar recuperar esses outros sentidos políticos que permanecem inexplorados. É aqui que surgem as lembranças pessoais e a dimensão afetiva, com referências a esperanças, expectativas, euforias e frustrações, que emergem em rememorações durante conversas e entrevistas com organizadores e participantes; surgem também as marcas na própria cidade de Porto Alegre (e em outros suportes materiais que guardam sinais do vivido); revelam-se ainda coleções de materiais e lembranças não sistematizadas e nem acessíveis ao público, guardadas por pessoas em suas casas ou esquecidos no canto de alguma ONG ou repartição pública. Di Giovanni nos lembra de que todos esses restos e vestígios, apesar de terem sido suprimidos e de não estarem nas programações inscritas ou nas memórias sistematizadas, fazem parte do Fórum e dos engajamentos que se produziram em torno dos eventos.

O livro Cadernos de outro mundo oferece, assim, contribuições importantes. É um exemplo de investigação que explora a relação entre militante e etnógrafo, menos por tomar essa relação como tema de discussão e mais por usar a posição de maneira analítica, procurando pensar o Fórum nos seus próprios termos e, ao mesmo tempo, problematizar pontos que permaneciam pouco explorados pela literatura do tema. A discussão sobre os usos e sentidos da metodologia no Fórum oferece um importante exemplo etnográfico àqueles interessados em pensar a relação entre técnica e política, constituindo-se ainda como caso paradigmático das ditas "novas políticas". Finalmente, a análise sobre a construção da memória do Fórum ilumina a centralidade da dimensão e dos processos re- 
lativos às sensibilidades e emoções para o engajamento político, evidenciando o enraizamento dos processos de organização política em dimensões ordinárias do cotidiano, ao mesmo tempo que demonstra como memórias não se referem apenas, ou especialmente, ao passado, posto que são práticas criativas que dizem respeito também ao presente e ao futuro.

\section{autora Lorena Avellar de Muniagurria}

Doutora em Antropologia Social pela Universidade de São Paulo (USP) desde 2016. Possui graduação em Ciências Sociais pela Universidade Federal do Rio Grande do Sul (2003) e mestrado em Antropologia Social pela mesma instituição (2006). Atualmente, integra o Coletivo ASA - artes saberes e antropologia, do PPGAS/USP.

Recebido em 06/12/2016

Aceito para publicação em 09/01/2017 